\title{
Boiling Heat Transfer Enhancement by Using Micro-pin-finned Surface for Electronics Cooling
}

\author{
Jinjia Wei • Jianfu Zhao • \\ Minzhe Yuan • Yanfang Xue
}

Received: 30 January 2009 / Accepted: 28 May 2009 / Published online: 13 June 2009

(C) Springer Science + Business Media B.V. 2009

\begin{abstract}
For efficiently cooling electronic components with high heat flux, experiments were conducted to study the flow boiling heat transfer performance of FC-72 over square silicon chips with the dimensions of $10 \times 10 \times 0.5 \mathrm{~mm}^{3}$. Four kinds of micro-pin-fins with the dimensions of $30 \times 60,30 \times 120,50 \times 60,50 \times$ $120 \mu^{2}$ (thickness, $t \times$ height, $h$ ) were fabricated on the chip surfaces by the dry etching technique for enhancing boiling heat transfer. A smooth surface was also tested for comparison. The experiments were made at three different fluid velocities $(0.5,1$ and $2 \mathrm{~m} / \mathrm{s})$ and three different liquid subcoolings (15, 25 and $35 \mathrm{~K})$. The results were compared with the previous published data of pool boiling. All micro-pin-fined surfaces show a considerable heat transfer enhancement compared with a smooth surface. Flow boiling can remarkably decrease wall superheat compared with pool boiling. At the velocities lower than $1 \mathrm{~m} / \mathrm{s}$, the micro-pin-finned surfaces show a sharp increase in heat flux with increasing wall superheat. For all surfaces, the maximum allowable heat flux, $q_{\max }$, for the normal operation of LSI chips increases with fluid velocity and subcooling. For all micro-pin-finned surfaces, the wall temperature at the critical heat flux (CHF) is less than the upper limit for the reliable operation of LSI chips, $85^{\circ} \mathrm{C}$. The
\end{abstract}

J. Wei $(\bowtie) \cdot$ M. Yuan · Y. Xue

State Key Laboratory of Multiphase Flow in Power

Engineering, Xi'an Jiaotong University,

Xi'an 710049, China

e-mail: jjwei@mail.xjtu.edu.cn

\section{J. Zhao}

National Microgravity Laboratory,

Institute of Mechanics, Chinese Academy of Sciences,

15 Beisihuan Xilu, Beijing 100190, China largest value of $q_{\max }$ can reach nearly $148 \mathrm{~W} / \mathrm{cm}^{2}$ for micro-pin-finned chips with the fin height of $120 \mu \mathrm{m}$ at the fluid velocity of $2 \mathrm{~m} / \mathrm{s}$ and the liquid subcooling of $35 \mathrm{~K}$. The perspectives for the boiling heat transfer experiment of the prospective micro-pin-finned surfaces, which has been planned to be made in the Drop Tower Beijing/NMLC in the future, are also presented.

Keywords Boiling heat transfer enhancement • Electronics cooling $\cdot$ High heat flux $\cdot$ Micro-pin-fin • FC-72 $\cdot$ Microgravity

\section{Introduction}

With rapidly increasing power dissipation rate for electronic components, sophisticated electronic cooling technology is required to maintain relatively constant component temperature below the junction temperature, approximately $85^{\circ} \mathrm{C}$ for most mainframe memory and logic chips. Traditional convection heat transfer from electronic hardware to the surroundings has been achieved through the natural, forced, or mixed convection of air; however, even with advances in air-cooling techniques, the improvements will not suffice to sustain the expected higher heat fluxes. As an effective and increasingly-popular alternative to air cooling, directly immersing the component in inert, dielectric liquid can remove a large amount of heat dissipation, of which pool and forced boiling possess the attractive attribute of large heat transfer coefficient due to phase change compared with single-phase.

An ideal boiling performance should provide adequate heat removal within acceptable chip temperatures. Primary issues related to direct liquid cooling 
of electronics are the mitigation of incipience temperature overshoot, enhancement of established nucleate boiling and elevation of the critical heat flux (CHF). Microstructured surfaces have been found to be very effective in enhancing boiling heat transfer. Since the 1970s, a number of active studies have dealt with the enhancement of boiling heat transfer from electronic components by use of surface microstructures that were fabricated directly on a silicon chip or on a simulated chip. These include sand paper or sandblasted and $\mathrm{KOH}$ treated surfaces (Messina and Park 1981; Anderson and Mudawar 1989; Oktay 1982), a dendritic heat sink (a brush-like structure) (Oktay 1982; Oktay and Schmekenbecher 1972), laser-drilled holes (3-15 $\mu \mathrm{m}$ in mouth dia.) (Hwang and Moran 1981), re-entrant cavities (0.3-0.5 $\mu \mathrm{m}$ in mouth dia.) (Phadke et al. 1992), micro-re-entrant cavities (1-3 $\mu \mathrm{m}$ in mouth dia.) (Kubo et al. 1999), hexagonal dimples (11.5 $\mu \mathrm{m}$ across and $4.1 \mu \mathrm{m}$ deep) and regular trenches $(12.6 \mu \mathrm{m}$ wide, $51 \mu \mathrm{m}$ deep and $101 \mu \mathrm{m}$ long) by photo-etching (Wright and Gebhart 1989), heat sink studs with drilled holes, micro-fins with and without microporous coating, micro-channels and pores, etc. $(0.2-12 \mathrm{~mm}$ in feature size) (Anderson and Mudawar 1989; Nakayama et al. 1982), porous surfaces formed by spraying and painting of alumina particle $(0.3-5 \mu \mathrm{m}$ or $1-20 \mu \mathrm{m}$ in dia.), silver flakes $(3-10 \mu \mathrm{m}$ in dia.) or diamond particle (1-12 $\mu \mathrm{m}$ in dia.), and copper particle $(3-10 \mu \mathrm{m}$ in dia.) (O'Connor et al. 1995, 1996; O'Connor and You 1995; Chang and You 1996), porous metallic matrix surface by brazing metal powder to the base surface (50-60\% void fraction) (Bergles and Chyu 1982). All above treated surfaces experienced the drawback of severely deterioration of boiling heat transfer at the high heat flux region and the wall temperature at the critical heat flux $(\mathrm{CHF})$ is larger than the upper limit for the reliable operation of LSI chips, $85^{\circ} \mathrm{C}$. Mudawar's group (Ujereh et al. 2007) studied the nucleate pool boiling enhancement by use of carbon nanotube (CNT) arrays, and found CNTs were quite effective in reducing incipience superheat and enhancing the boiling heat transfer coefficient. It is still a challenge for this treated surface to increase CHF by a large margin for the application of cooling with high-heat-flux chip.

Since 2002, Honda and Wei (Honda et al. 2002; Wei and Honda 2003; Wei et al. 2005, 2007) have made a series of experimental study on pool boiling enhancement by use of micro-pin-fins $(10-50 \mu \mathrm{m}$ in thickness and $60-200 \mu \mathrm{m}$ in height) which were fabricated by dry etching. From the boiling incipience to the critical heat flux, the micro-pin-finned surfaces showed a sharp increase in the heat flux with increasing wall superheat. The increase of CHF could reach more than twice that of a smooth chip and the wall temperature at the $\mathrm{CHF}$ point was lower than $85^{\circ} \mathrm{C}$. The micro-pinfined surface appears to be one promising enhanced surface for electronic components cooling schemes. However, the micro-pin-finned surface was only tested in a pool of FC-72, and its enhancement ability under flow boiling is not yet revealed. Some researchers such as Mudawar and Maddox (1989), Kutateladze and Burakov (1989) and Rainey et al. (2001) have found that both of fluid velocity and subcooling had significant positive effects on the nucleate boiling curve and the critical heat flux of their thin film heater. Therefore, the objective of this paper is to study the combined effects of fluid velocity and subcooling on the flow boiling heat transfer of FC-72 over micro-pin-fined surfaces for further enhancement of boiling heat transfer to cool high-heat-flux devices. Four kinds of micro-pin-finned chips having the fin thickness of 30 and $50 \mu \mathrm{m}$ and the fin heights of 60 and $120 \mu \mathrm{m}$ were tested. A smooth chip was also tested for comparison. The results are also compared with previous published data of pool boiling and other reported enhanced surfaces (Honda et al. 2002; Wei and Honda 2003; Wei et al. 2005; Rainey et al. 2001; Lie et al. 2007).

\section{Experimental Apparatus and Procedure}

Figure 1 shows the schematic diagram of the flow boiling test facility, which was a closed-loop circuit consisting of a tank, a scroll pump, a test section, two heat exchangers and a turbine flowmeter. The tank served as a fluid reservoir and pressure regulator during testing. To ensure proper inlet pressure control, a pressure transducer was installed at the inlet of the test section. The pressure drop across the test section was also measured by a pressure difference transducer. The flowmeter and the sensors for pressure and pressure difference had the function of outputting 4 20 mA current signals and were measured directly by a data acquisition system. The condenser prior to the pump was used to cool the fluid and prevent cavitation in the pump. The pump combined with a converter was used to control the mass flow rate. The pre-heater prior to the test section was used to control the test section inlet temperature.

Details of the test section are shown in Fig. 2. The test chip was a P-doped N-type square silicon chip with the dimensions of $10 \times 10 \times 0.5 \mathrm{~mm}^{3}$. The chip was bonded on a substrate made of polycarbonate using epoxy adhesive, and fixed in the horizontal, upward facing orientation on the bottom wall of a horizontal 
Fig. 1 Schematic diagram of flow boiling test loop

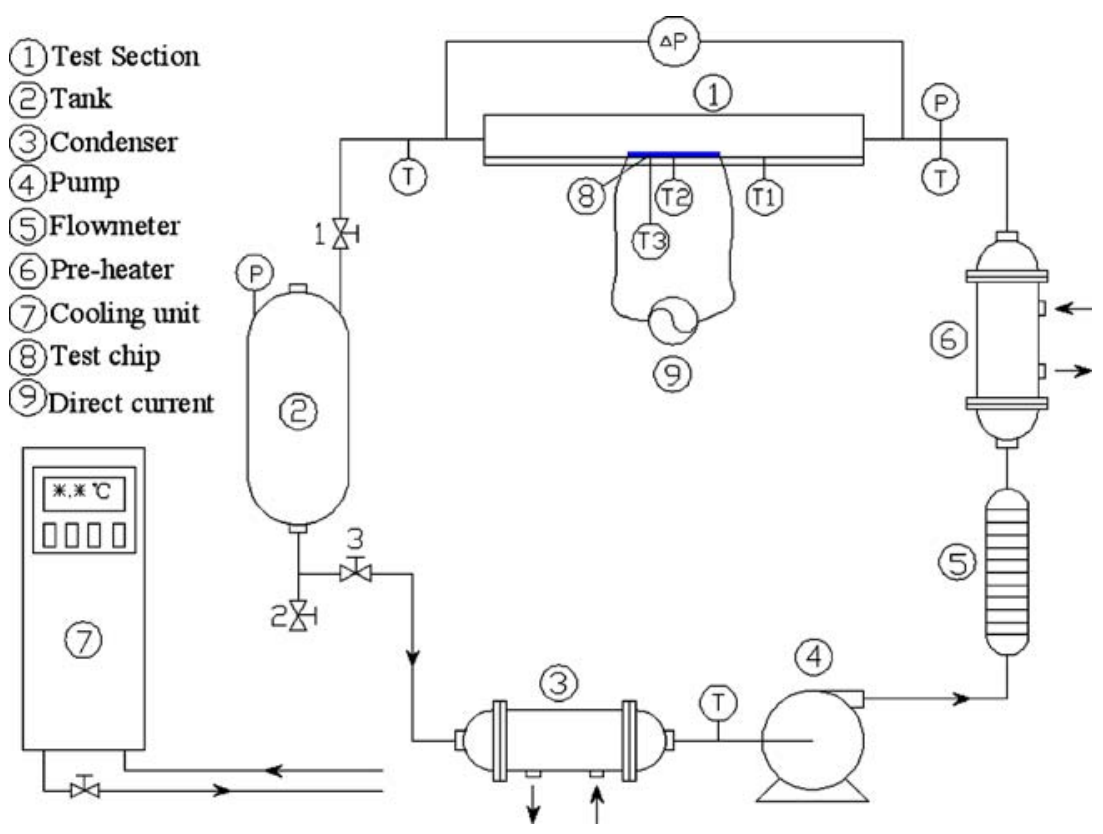

channel which is $5 \mathrm{~mm}$ high and $30 \mathrm{~mm}$ wide. The chip was located $300 \mathrm{~mm}$ (60 hydraulic dia.) from the test section inlet so that the fluid flow at it was estimated to be fully developed turbulent flow for the present fluid velocity range. The side surfaces of the chip were covered with adhesive to minimize heat loss. Therefore, only the upper surface of the chip was effective for heat transfer. The chip was joule heated by using a programmable d.c. power supply. Two $0.25 \mathrm{~mm}$ diameter copper wires for power supply and voltage drop measurement were soldered to the side surfaces of the chip at the opposite ends. A special solder with the higher melting point of $300^{\circ} \mathrm{C}$ was used for securing the ohmic contact between the semiconductor silicon chip and the copper wire, and the solder with the lower melting point of $180^{\circ} \mathrm{C}$ was then used for bonding the copper wire with the chip. For measuring chip temperature, two $0.12 \mathrm{~mm}$ dia. T-type thermocouples for the local wall temperature measurement were adhered under the test chip at the center and at about $1.5 \mathrm{~mm}$ from the downstream end.

The test channel on the bottom of which the test chip was fixed was made of Pyrex glass for visualizing flow boiling phenomena by use of a high speed video. To prevent the liquid from leaking out, the upper and nether covers were fastened by bolts and were seal with an O-ring. The local temperature of the test liquid at the chip level was measured by a T-type thermocouple the hot junction of which was located upstream on a vertical line $25 \mathrm{~mm}$ apart from the edge of the test chip. The measured temperature was used as the bulk temperature of test fluid, $T_{b}$.

Fig. 2 Schematic diagram of test section

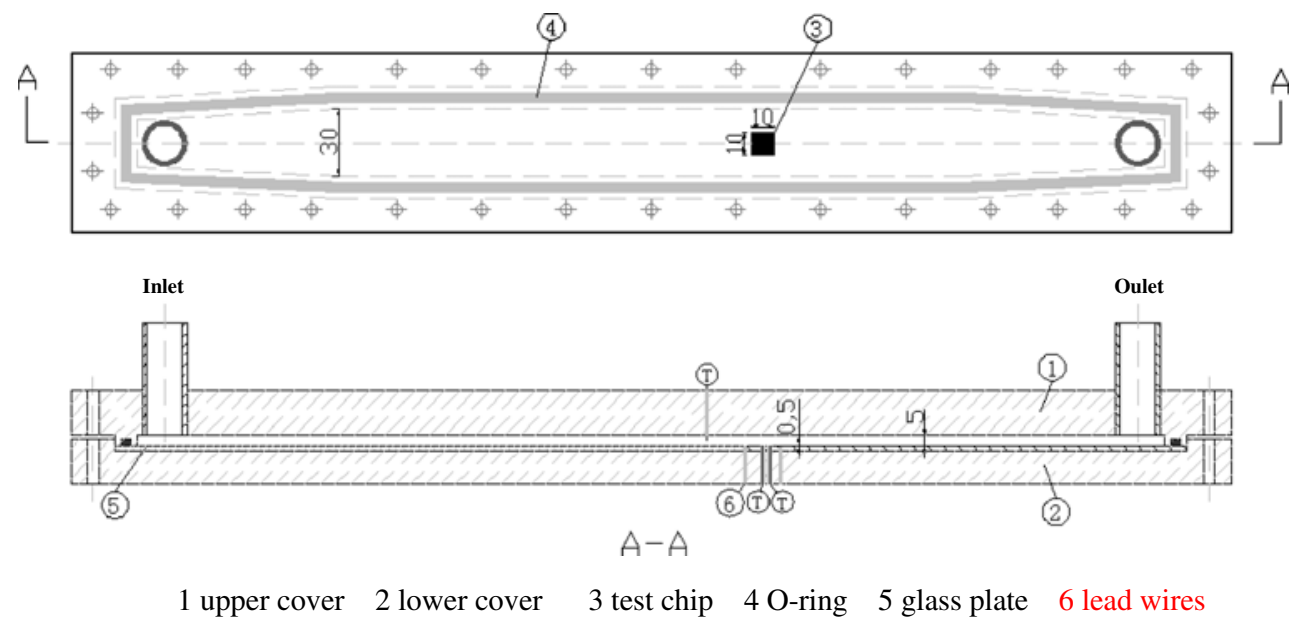


For enhancing boiling heat transfer, micro-pin-fins with square cross-sections were fabricated on the surface of silicon chip by use of the dry etching technique. The capillary force generated by the bubbles resting on the micro-pin-fins in the boiling procedure drives plenty of fresh liquid into contact with the superheated wall for vaporization through the regular interconnected structures formed by micro-pin-fins, as well as improves the micro-convection heat transfer by the motion of liquid around the micro-pin-fins. The capillary force increases with decreasing fin pitch with a penalty that causes the hydraulic resistances of the wet liquid supply to increase. Therefore, there exists an optimum fin pitch for a compromise. In our previous experimental study for pool boiling case (Wei and Honda 2003), we tested a series of micro-pin-fins with different fin sizes and found that the fin gap of 30-50 $\mu \mathrm{m}$ appears to be a preferable size for enhancing nucleate boiling heat transfer. Therefore, we selected the micro-pin-fins with the thicknesses of 30 and $50 \mu \mathrm{m}$ in the present study. To study the combined effects of fin thickness, $t$, and fin height, $h$, four kinds of micro-pin-finned chips having the fin dimensions of $30 \times 60,30 \times 120$, $50 \times 60,50 \times 120 \mu^{2}(t \times h)$, named chips PF30-60, PF30-120, PF50-60 and PF50-120, respectively, were tested. The fin pitch $p$ was twice the fin thickness. The surface area ratio $A_{\mathrm{t}} / A$ is $1,2.2,3.4,3$ and 5 for chips S, PF50-60, PF50-120, PF30-60 and PF30120 , respectively. $A_{\mathrm{t}}$ is the total surface area and $A$ is the projected surface area of the chip. The scanningelectron-micrograph (SEM) images of the four micropin-finned chips are shown in Fig. 3a-d, respectively. A smooth chip was also tested for comparison. Experiments were performed at the fluid velocities $V$ of 0.5 , 1 and $2 \mathrm{~m} / \mathrm{s}$ and liquid subcoolings $\Delta T_{\text {sub }}$ of 15,25 and $35 \mathrm{~K}$.

After FC-72 was filled into the loop, a frequency converter was used to increase the mass flow rate of the pump to a required fixed value. Then a cooling unit was run to control the liquid temperature in channels. When the loop reached steady state, the power supply was initiated to heat the test chip. The power supply was connected to a standard resistor $(1 \Omega)$ and the test chip. The standard resistor was used to measure the electric current in the circuit. The heat flux, $q$, (defined on the projected area basis) was obtained from the voltage drop of the test chip and the electric current. Power input to the test chip was increased in small steps up to the high heat flux region of nucleate boiling. After each current increase (heat flux increment), a short time delay was imposed to make sure that a steady-state condition was attained. Then e.m.f.s of the thermocouples for the wall temperature and liquid temperature measurements and the voltage drops of the test chip and the standard resistor were read and recorded by a data acquisition unit with a frequency of $20 \mathrm{~Hz}$ for about 1-2 min, and the average values of these measurements during the steady period were
Fig. 3 SEM images of micro-pin-fins. a Chip PF30-60. b Chip PF30-120. c Chip PF50-60. d Chip PF50-120

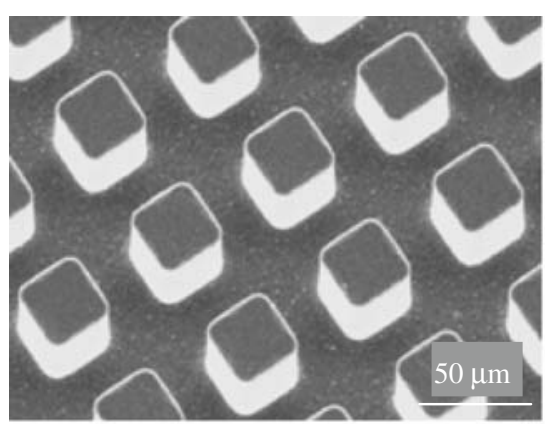

(a) Chip PF30-60

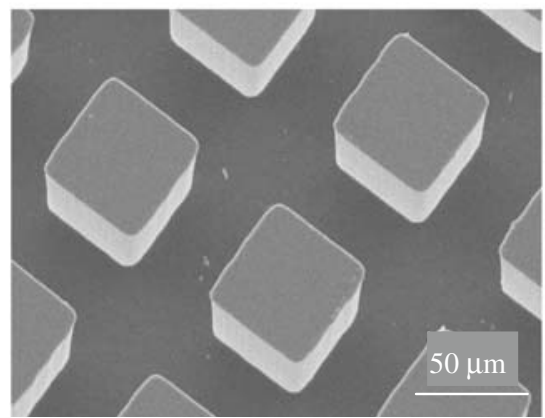

(c) Chip PF50-60

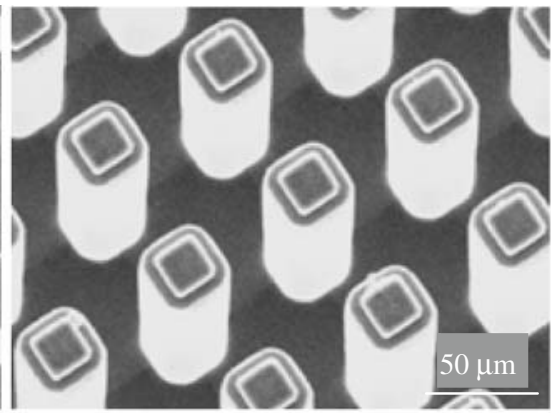

(b) Chip PF30-120

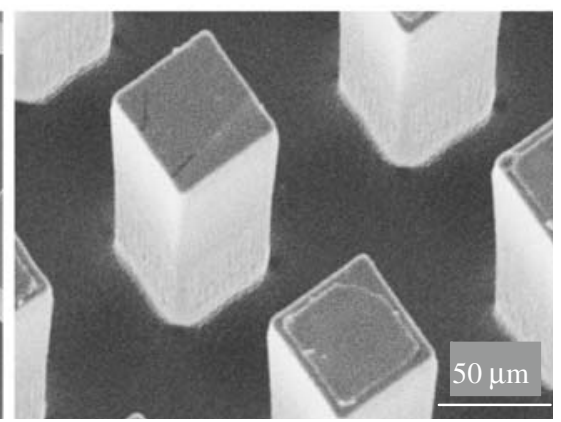

(d) Chip PF50-120 
adopted as experimental data. The wall temperature $T_{\mathrm{w}}$ was defined by the measured value at the center on the back surface of the test chip.

For heat flux greater than $90 \%$ of the CHF, the input current steps were reduced to a smaller value. An overheating protection system was incorporated in the power circuit. If the wall temperature sharply increases by more than $20 \mathrm{~K}$ in a short time, the data acquisition algorithm assumed the occurrence of CHF condition and the power supply was immediately shut down. The CHF value was computed as the steady state heat flux value just prior to the shutdown of the power supply.

The uncertainties in the chip and bulk liquid temperature measurements by the thermocouples are estimated to be less than $0.3 \mathrm{~K}$. Wall temperature uncertainty can be attributed to the errors caused by thermocouple calibration by a platinum resistance thermometer $(0.03 \mathrm{~K})$, temperature correction for obtaining surface temperature from the measured value at the bottom of the chip $(0.2 \mathrm{~K})$, the temperature unsteadiness $(0.1 \mathrm{~K})$ and the thermocouple resolution (less than $0.1 \mathrm{~K}$ ). The uncertainty of the bulk temperature is due to errors caused by thermocouple calibration by a platinum resistance thermometer $(0.03 \mathrm{~K})$, the temperature unsteadiness $(0.2 \mathrm{~K})$ and the thermocou- ple resolution (less than $0.1 \mathrm{~K}$ ). Heat flux uncertainty includes the error of electric power supplied to the chip $(0.11 \%)$, which is calculated from the errors of the current $(0.014 \%)$ and voltage $(0.1 \%)$ across the chip and heat loss by substrate heat conduction. The heat loss is estimated by solving three-dimensional conduction problems through substrate using a commercial software FLUENT with the measured wall temperature as a given condition, which is less than $16 \%$ and $6 \%$ for the forced convection and the nucleate boiling regions, respectively. It should be mentioned that $q$ includes the heat transferred to the bulk liquid by conduction through the polycarbonate substrate.

\section{Results and Discussion}

Flow and Pool Boiling Performance of Micro-pin-Finned Surfaces

Figure 4 shows the boiling curves of chips PF30-60 and PF30-120, at $\Delta T_{\text {sub }}=25 \mathrm{~K}$ for both flow boiling and pool boiling cases. For comparison, the flow and pool boiling curves of a smooth chip, chip S, and O'Connor et al. (1996) and boiling curves of Rainey et al. (2001)
Fig. 4 Boiling curves of chips PF30-60, PF30-120 and S, $\Delta T_{\text {sub }}=25 \mathrm{~K}$

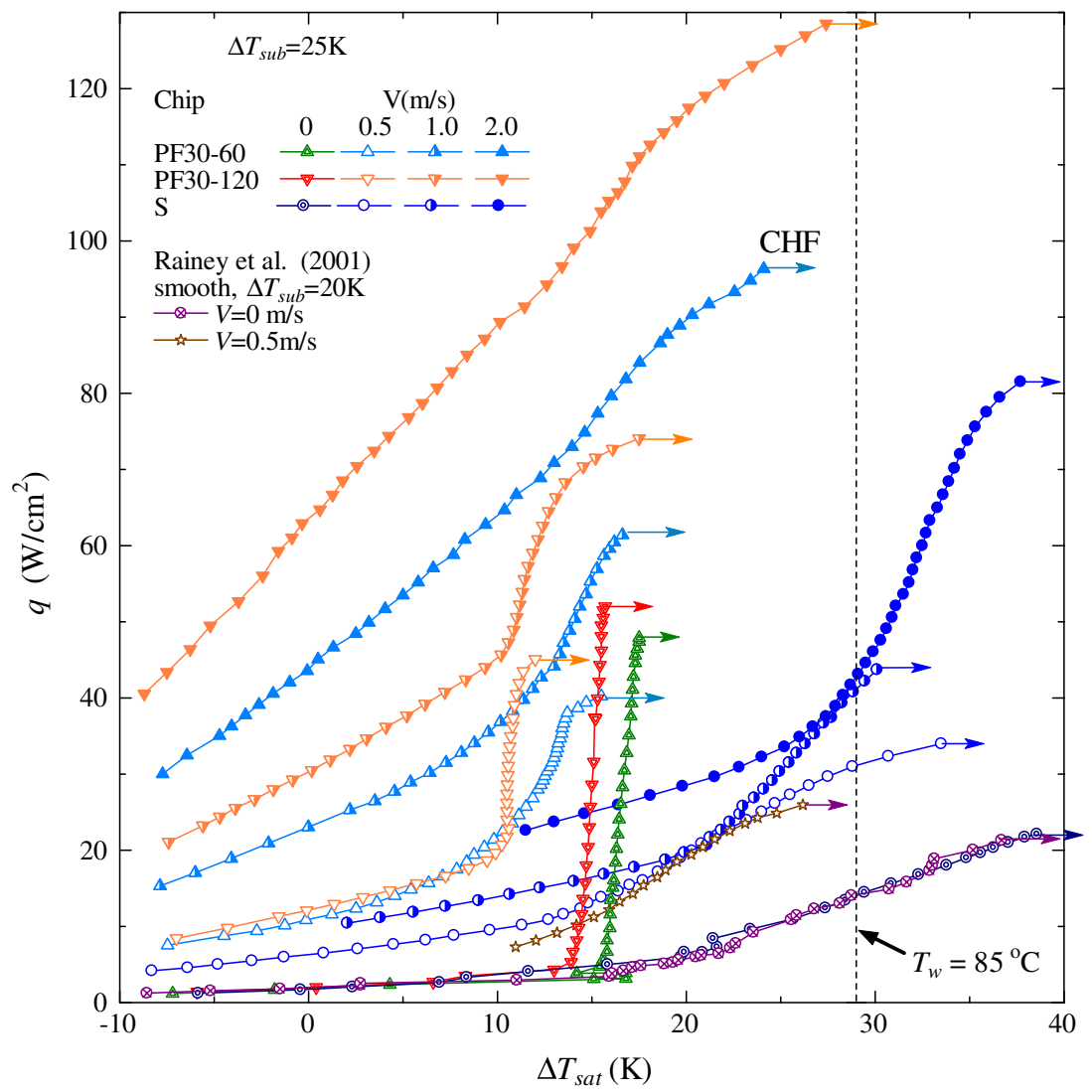


with the liquid subcooling of $20 \mathrm{~K}$ for their smooth surface at 0.5 and $0 \mathrm{~m} / \mathrm{s}$ are also shown in Fig. 4. The pool boiling data are obtained from our previously published work (Wei and Honda 2003). Both the flow and pool boiling curves of the smooth surfaces of O'Connor et al. (1996) and Rainey et al. (2001) agree well with those of chip S except for a lower CHF value due to the lower liquid subcooling.

For the flow boiling case, the single-phase, forced convection curves for the micro-pin-finned surfaces show much higher heat flux than those for the smooth surface due to the total surface increase, and increase with the total surface area in the order of chips S, PF30-60, PF30-120, indicating that the side walls of the micro-pin-fins are exposed to the fluid flow and are active for the forced convection heat transfer. This differs from the natural convection heat transfer for the pool boiling case, where the natural convection curves are not affected by the micro-pin-fins since they are completely submerged in the thermal boundary layer of superheated liquid.

In the nucleate boiling region, we can see that the boiling curves are greatly affected by fluid velocity, and the wall superheat decreases with increasing fluid velocity at a given heat flux for the same surface. This indicates that the forced convection also play a very important role for the total heat transfer besides the nucleate boiling heat transfer. The slope of the boiling curve decreases with increasing fluid velocity, indicating that the proportion of forced convection heat transfer increases with fluid velocity. Especially for the fluid velocity of $2 \mathrm{~m} / \mathrm{s}$, the slope of the nucleate boiling curves are only slightly larger than that of the forced convection heat transfer curves, showing that the forced convection dominates the heat transfer performance.

The wall superheats at the same heat flux decrease and the critical heat flux increase in the order of chip S, PF30-60, PF30-120 for the same velocity, which shows that all micro-pin-fined surfaces have considerable heat transfer enhancement compared with a smooth surface. The enhancement of the heat transfer is considered as the surface area increase of the micro-pin-finned chip over a smooth surface. Observation of boiling phenomena on the micro-pin-finned chip revealed that this surface can cause more active nucleation sites, and makes the bubbles rest on surface for a longer time for evaporation. The capillary force generated by the bubbles resting on the micro-pin-fins drives plenty of fresh liquid to contact with the superheated wall for vaporization through the regular interconnected structures formed by micro-pin-fins, as well as improves the micro-convection heat transfer by the motion of liquid around the micro-pin-fins, and thus increases the heat transfer performance too. The wall temperature at the $\mathrm{CHF}$ point is less than the upper limit for the reliable operation of LSI chips, $85^{\circ} \mathrm{C}$.

For the micro-pin-finned surface, the ratio of fin height to fin pitch, $h / p$, and fluid velocity are key parameters for determining the boiling heat transfer. When $h / p$ is very small and/or fluid velocity is very large, the bubble nucleation on the bottom and side wall surfaces of the micro-pin-fin is easily affected by the forced flow over the chip surface, which prevents the burst of nucleate bubbles and thus reduces the proportion of nucleate boiling heat transfer. Therefore, the large effect of fluid velocity leads to a large deviation of the pool boiling curve from the flow boiling curves. Different from the smooth surface as shown in Fig. 4, the slopes of the pooling boiling curves for chips PF30-60 and PF30-120 are much larger than that of the flow boiling curve. As explained by Wei et al. (2005), the micro-convection and thin liquid layer evaporation due to the bubble generation in the gap between micro-pin-fins are the reason for the significant enhancement of pool boiling heat transfer. For the micro-pin-finned surface with a lower $h / p$, the bubble nucleation is largely affected by the fluid flow, reducing the boiling heat transfer enhancement. The value of $h / p$ is 2 and 1 for chips PF30 120 and PF30-60 respectively. Therefore, the boiling curves of chip PF30-120 is less affected than that of chip PF30-60, showing a larger slope. It can be seen in Fig. 4 that the $\mathrm{CHF}$ at $0.5 \mathrm{~m} / \mathrm{s}$ for the flow boiling is lower than that for the pool boiling. For the pooling boiling heat transfer (Wei and Honda 2003), the test chips were immersed in a large pool of FC-72, and there was a large distance from the chip surface to the ceiling of the test vessel. The rising bubbles from the heater surface condensed before they could impinge the ceiling. The observation of flow boiling phenomena at $V=0.5 \mathrm{~m} / \mathrm{s}$ shows that there are large bubbles over the chip surface at high heat fluxes, which impinge the upper wall of the test channel due to the small channel height of $5 \mathrm{~mm}$. The lower fluid velocity of $0.5 \mathrm{~m} / \mathrm{s}$ cannot push the bubbles away downstream immediately, and thus the liquid cannot access to the chip surface easily due to the bubble blockage, resulting in an earlier heater burnout, i.e., CHF. This phenomenon was also observed in the boiling heat transfer experiment in a natural circulation loop where the test channel was also only $5 \mathrm{~mm}$ high (Wei et al. 2007).

Figure 5 shows the boiling curves of chips PF50-60, PF50-120 and $\mathrm{S}$ at $\Delta T_{\text {sub }}=25 \mathrm{~K}$ for both flow boiling and pool boiling cases. For comparison, the flow and pool boiling curves of the smooth surface of Rainey et al. (2001) with the liquid subcooling of $20 \mathrm{~K}$ at $V=0.5 \mathrm{~m} / \mathrm{s}$ and $0 \mathrm{~m} / \mathrm{s}$ are also shown in Fig. 5 . It can 
Fig. 5 Boiling curves of chips PF50-60, PF50-120 and S, $\Delta T_{\text {sub }}=25 \mathrm{~K}$

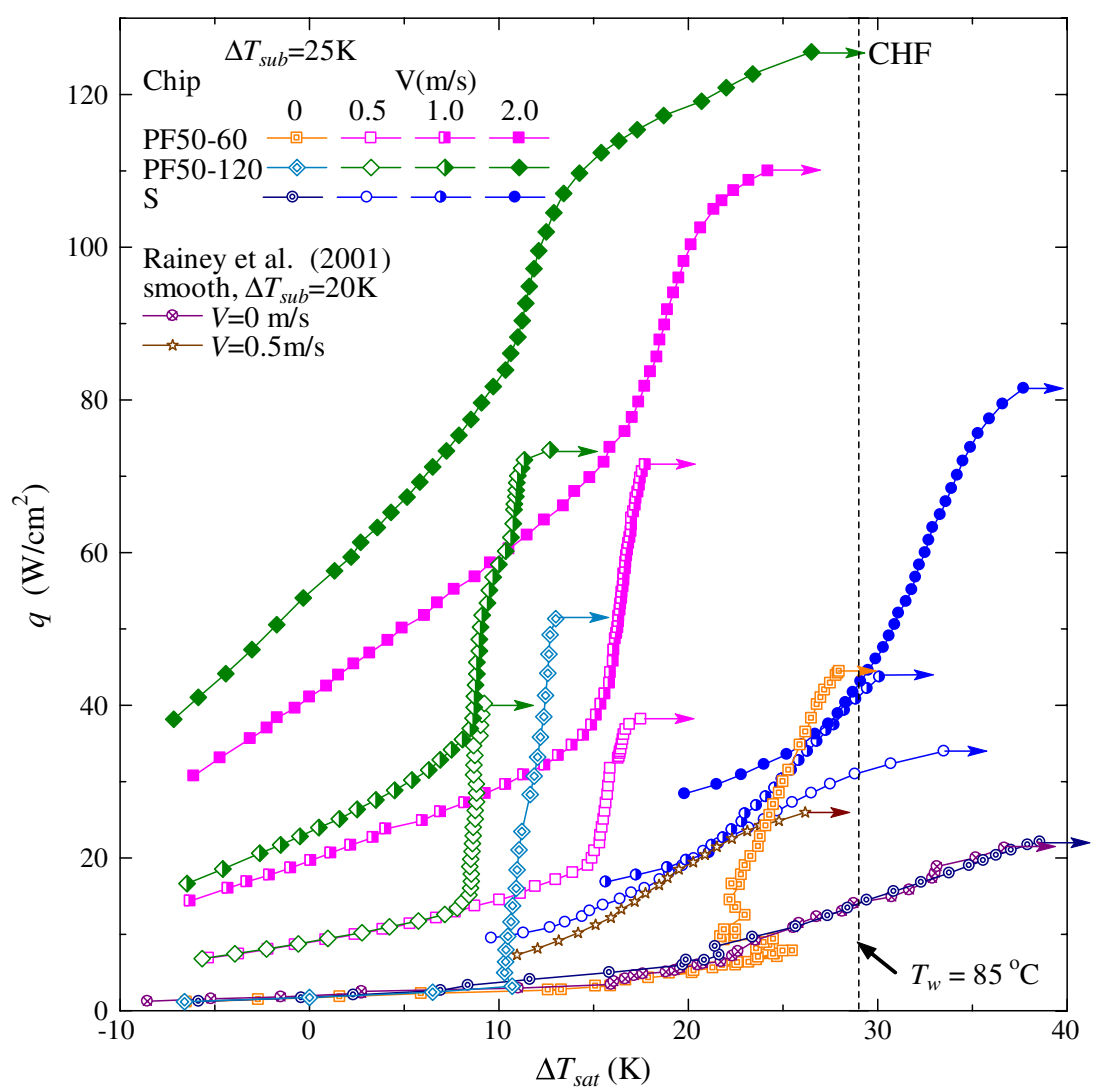

be seen that the slope of boiling curves increase in the order of chip S, PF50-60, PF50-120 for the same velocity, which shows that the $50-\mu \mathrm{m}$ thick micro-pinfins also have considerable heat transfer enhancement compared with a smooth surface since they increase the total heat transfer surface area on the chip. The wall superheats decrease and the CHFs increase in the order of chip S, PF50-60, PF50-120, and the wall temperature at the CHF point is less than the upper limit for the reliable operation of LSI chips, $85^{\circ} \mathrm{C}$, showing that the heat transfer is enhanced by increasing total heat transfer surface area. Careful comparison of flow boiling curves for different fluid velocities shows that the boiling curves in the nucleate region are almost not affected for $V<2 \mathrm{~m} / \mathrm{s}$, indicating that the nucleate boiling dominates the heat transfer process. The slope of the boiling curves at $V=2 \mathrm{~m} / \mathrm{s}$ becomes slightly smaller than that at lower velocities, indicating that the forced convection heat transfer starts to have a certain effect but not enough to play a dominant role. The flow boiling curves shift toward a smaller wall superheat compared with the pool boiling curves for the same micro-pin-finned chip PF50-60 or PF50-120. The $\mathrm{CHF}$ increases with increasing fluid velocity for the flow boiling. However, the CHF is lower for the flow boiling at $V=0.5 \mathrm{~m} / \mathrm{s}$ than that for the pool boiling with the same reason explained for chips PF30-60 and PF30-120 previously.

Figure 6 shows the comparison of boiling curves for all surfaces with $\Delta T_{\text {sub }}=15 \mathrm{~K}$. For the fluid velocity $V<2 \mathrm{~m} / \mathrm{s}$, the wall superheat in the nucleate boiling region decreases in the order of chip S, PF50-60, PF3060 , PF30-120 for the same fluid velocity, again showing that the boiling heat transfer can be enhanced by increasing total surface area. However, the boiling curve of chip PF50-120 shows the smallest wall superheat despite of the surface area ratio of 3.4. Although the condition for the etching process is set to the same, the etching size is different for different micro-pin-finned chips, which may affect the etching results. From the scanning-electron-micrograph (SEM) image of micropin-fins (Fig. 3), we found that the roughness on the fin flank near the fin root usually increases with increasing etching depth. Chip PF50-120 with the largest fin thickness and height is observed to have a large roughness scale on the fin flank. It is considered that the roughness causes the earlier boiling incipience and thus smaller wall superheat in the nucleate boiling region. For the fluid velocity of $2 \mathrm{~m} / \mathrm{s}$, the nucleate boiling curves of all micro-pin-finned chips are more or less affected by forced convection heat transfer since the slopes of boiling curves become smaller than those at lower 
Fig. 6 Comparison of flow boiling curves for all chips, $\Delta T_{\text {sub }}=15 \mathrm{~K}$

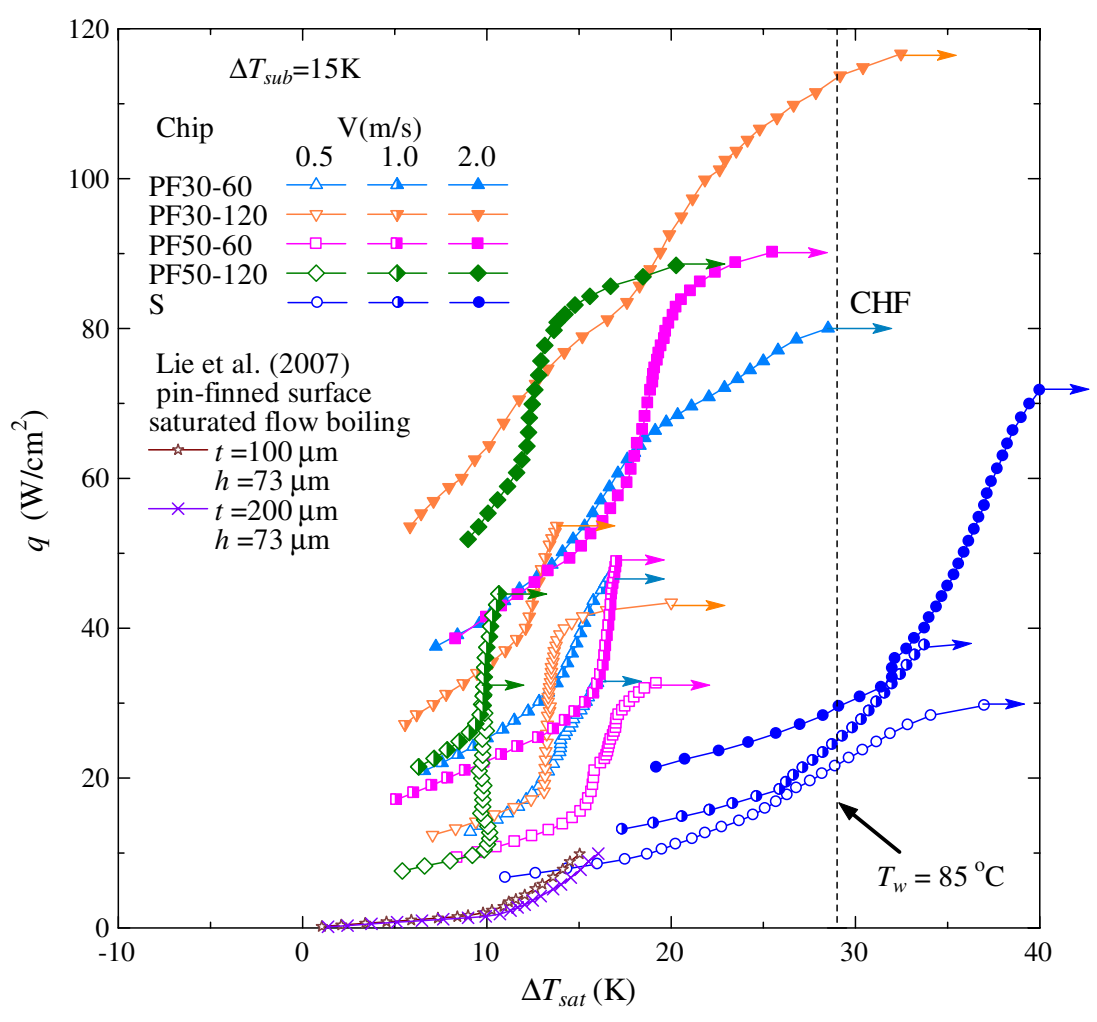

velocities, but the nucleate boiling curves of $50-\mu \mathrm{m}$ thick micro-pin-fins show a much larger slope than those of 30- $\mu \mathrm{m}$ thick micro-pin-fins. According to Wei et al. (2005), micro-convection caused by thermal capillary force in the micro-pin-fin formed interconnect tunnel plays an important role for boiling heat transfer. It is considered that bulk fluid flow may affect the microconvection greatly and the smaller fin gap of $30 \mu \mathrm{m}$ may generate a larger flow resistance for microconvection around the fin sidewalls, resulting in a lower heat transfer performance. The larger slope shifts the boiling curve of chips PF50-60 and PF50-120 to a smaller wall superheat than that of chips PF30-60 and PF30120 , respectively, at high heat flux for $V=2 \mathrm{~m} / \mathrm{s}$. For comparison, saturated boiling of Lie et al. curves for two pin-finned surfaces (Lie et al. 2007) are also shown in Fig. 6. The boiling curves of Lie et al. (2007) pinfinned surface with the larger fin thicknesses of 100 and $200 \mu \mathrm{m}$ show a much smaller slope and a larger wall superheat compared with that of the present micro-pinfinned surfaces. Generally, the wall superheat decreases in the order of 200, 100, 50 and 30- $\mu \mathrm{m}$ micro-pin-fins for the fin height of about $70 \mu \mathrm{m}$. We have found that the boiling heat transfer performance for the micropin-finned surface with the fin thickness of $10-50 \mu \mathrm{m}$ is much better than the pin-finned surface with the larger fin thickness of about $300 \mu \mathrm{m}$ used by Anderson and Mudawar (1989), and the fin thickness of 30-50 $\mu \mathrm{m}$ is a suitable range for effectively enhancing boiling heat transfer. The optimum fin gap size is considered to be determined by the balance of the capillary force caused by evaporation of bubbles for driving the micro-flow in the gap of micro-pin-fins and the flow resistance. Large fin gap usually has small flow resistance but generates small microconvection heat transfer proportion, and vice versa. The present flow boiling study again shows the larger fin thickness above $100 \mu \mathrm{m}$ is not so remarkably effective compared with the fin thickness of 30-50 $\mu \mathrm{m}$.

Figures 7 and 8 show the comparison of boiling curves for all surfaces with $\Delta T_{\text {sub }}=25$ and $35 \mathrm{~K}$, respectively. The trend of experimental data is basically the same as the case of $\Delta T_{\text {sub }}=15 \mathrm{~K}$ shown in Fig. 6 except that the values of the CHF increase considerably in the order of 25 and $35 \mathrm{~K}$. The highest value of $\mathrm{CHF}$ $\left(=148 \mathrm{~W} / \mathrm{cm}^{2}\right)$, about 1.5 times as large as that for the smooth surface, was obtained by chips PF30-120 and PF50-120 at $\Delta T_{\text {sub }}=35 \mathrm{~K}$ and $V=2 \mathrm{~m} / \mathrm{s}$. For comparison, boiling curve of Rainey et al. (2001) with the liquid subcooling of $20 \mathrm{~K}$ for the microporous surface at $V=2 \mathrm{~m} / \mathrm{s}$ is also shown in Fig. 7. The single-phase, forced convection curve of the microporous surface is worse than the smooth surface, chip $\mathrm{S}$, for the same velocity of $2 \mathrm{~m} / \mathrm{s}$, mainly due to the lower effective thermal conductivity of the microporous coating layer as explained by Rainey et al. (2001). Although having 
Fig. 7 Comparison of flow boiling curves for all chips, $\Delta T_{\text {sub }}=25 \mathrm{~K}$

Fig. 8 Comparison of flow boiling curves for all chips, $\Delta T_{\text {sub }}=35 \mathrm{~K}$
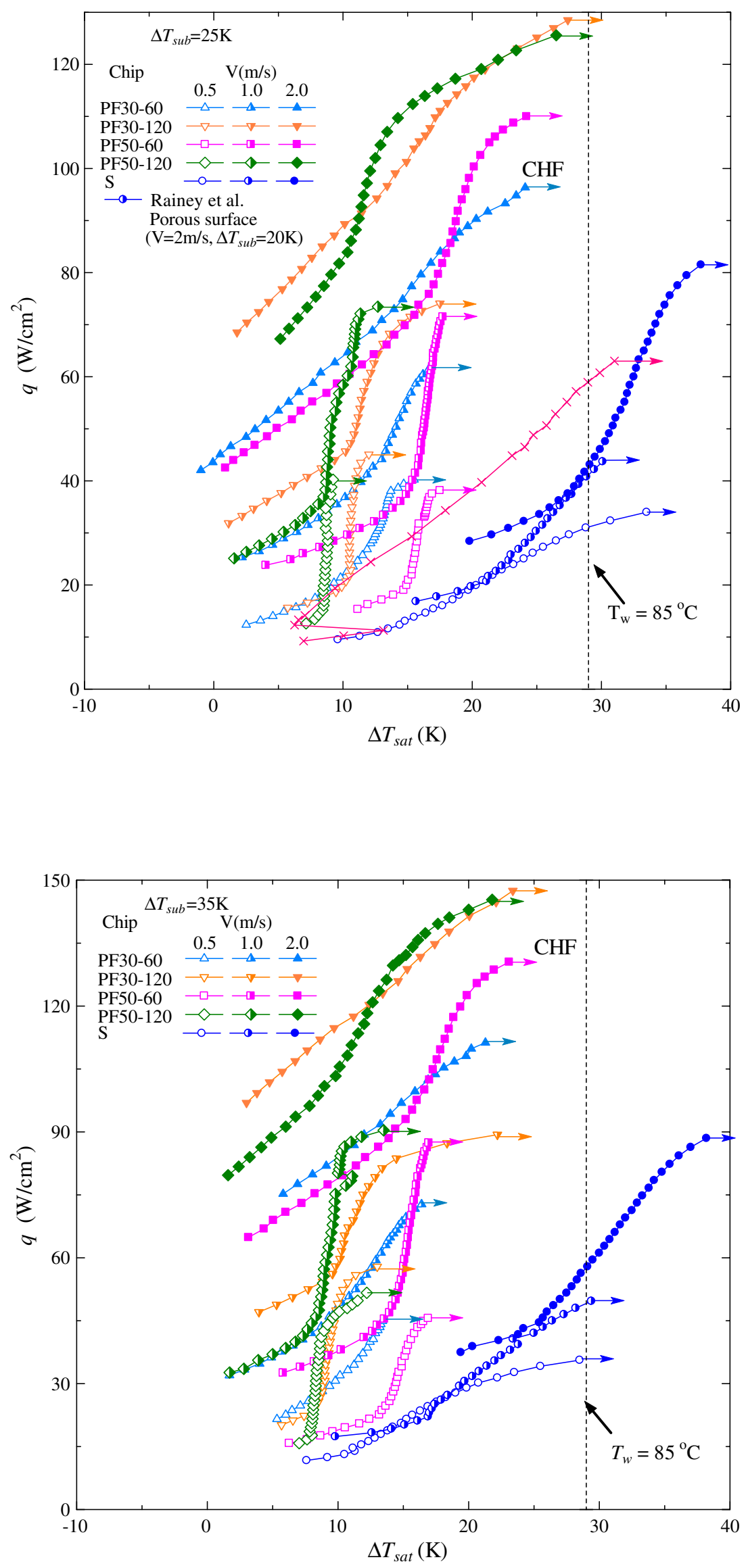
an earlier boiling incipience, the microporous surface shows a larger wall superheat than the micro-pin-finned surfaces in the nucleate boiling region, and the heat flux at $85^{\circ} \mathrm{C}$ is less than half the CHF of chips PF30-120 and PF50-120.

Careful comparison of flow boiling curves for different liquid subcoolings of 15,25 and $35 \mathrm{~K}$ shows that the boiling curves in the nucleate region are almost not affected by liquid subcooling for chips PF50-60, PF50-120, PF30-120 with $V<2 \mathrm{~m} / \mathrm{s}$, indicating that the nucleate boiling dominates the heat transfer process for these micro-pin-finned chips. For chip PF30-60, the boiling curves are affected by liquid subcooling due to a large effect of forced convection heat transfer.

The fluid velocity has a complicated effect on boiling heat transfer process. The flow velocity can deactive nucleation sites to worsen boiling heat transfer, but it can also push the large secondary bubbles on the heater surface away immediately for the access of fresh bulk liquid to the heater surface for enhancing boiling heat transfer. In general, the boiling heat transfer increases with increasing flow velocity, but the increment decreases due to the deactivation of nucleation sites by the high flow velocity. Therefore, the slope of boiling curves at flow velocity of $2 \mathrm{~m} / \mathrm{s}$ is smaller than those at 0.5 and $1 \mathrm{~m} / \mathrm{s}$, as shown in Figs. 4-8.

The pressure drops across the test section were also measured during the measurements of boiling heat transfer shown in Figs. 4-8. The measured pressure drops show almost the same values for different micropin-finned surfaces on the same flow and heat flux conditions, which are about 10,18 , and $35 \mathrm{kPa}$ at flow velocity of $0.5,1.0$ and $2.0 \mathrm{~m} / \mathrm{s}$, respectively, indicating that the microscale structures have no obvious effect on flow resistance.

As stated previously, the upper limit of temperature for a reliable operation of electronic chips is given by $85^{\circ} \mathrm{C}$. Thus the maximum allowable heat flux $q_{\max }$ is given by the CHF if $T_{\mathrm{w}, \mathrm{CHF}}<85^{\circ} \mathrm{C}$ and by $q$ at $T_{\mathrm{w}}=$ $85^{\circ} \mathrm{C}$ if $T_{\mathrm{w}, \mathrm{CHF}}>85^{\circ} \mathrm{C}$. We plot the relationship of $q_{\max }$ with fluid velocity for all surfaces with fluid subcooling as a parameter in Fig. 9. The fluid velocity has a very large effect on $q_{\max }$. Careful observation of the trends of $q_{\max }$ variation with fluid velocity shows that there exists a transition at $V=1 \mathrm{~m} / \mathrm{s}$ from low to high velocity, which is characterized by an increase of the rate of $q_{\max }$ enhancement for the low fluid subcooling of $15 \mathrm{~K}$. This transition was also reported by many researchers such as Mudawar and Maddox (1989), Rainey et al. (2001), and etc. However, for the larger liquid subcoolings of 25 and $35 \mathrm{~K}$, the transition from low to high velocity is characterized by a decrease in the rate of $q_{\max }$ enhancement with velocity. For a low fluid subcooling,

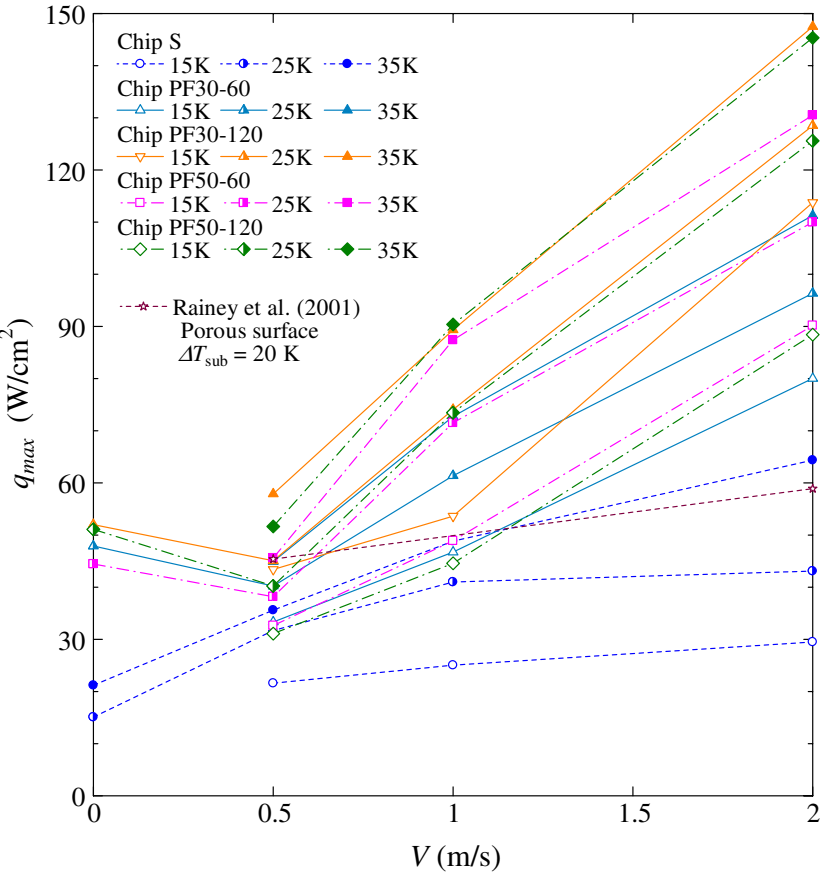

Fig. 9 Effects of fluid velocities and subcoolings on CHF

as explained by Mudawar and Maddox (1989), the low velocity $q_{\max }$ was caused by dryout of the liquid sublayer beneath a large continuous vapor blanket near the downstream edge of the heater; however in the high velocity $q_{\max }$ regime, the thin vapor layer covering the surface was broken into continuous vapor blankets much smaller than the heater surface, decreasing the resistance of fluid flow to rewet the liquid sublayer and thus providing an additional enhancement to $q_{\max }$ and subsequent increase in slope. For a large fluid subcooling, the bubble size becomes small and the heater surface was not fully occupied with vapor layer for the fluid velocity range in this study. The too large fluid velocity results in a large effect of forced convection heat transfer as shown in Figs. 4-8, reducing the nucleate boiling heat transfer to some extent. Moreover, from the slope of boiling curves we can see that the effect of the fluid velocity on micro-pin-fined surfaces is more noticeably compared with the porous surface (Rainey et al. 2001) and the smooth surface, and the enhancement of $q_{\max }$ sharply increases with fluid velocity. For chips PF30-120 and PF50-120, the $q_{\max }$ reaches nearly $148 \mathrm{~W} / \mathrm{cm}^{2}$ at $V=2 \mathrm{~m} / \mathrm{s}$ and $\Delta T_{\text {sub }}=35 \mathrm{~K}$. The pool boiling data of $q_{\max }$ for all surfaces at $\Delta T_{\text {sub }}=25 \mathrm{~K}$ are also shown in Fig. 9 for comparison. Except for chip S, $q_{\max }$ decreases from the pool boiling case to the flow boiling case. The reason maybe explained as follows. The micro-pin-finned surfaces can provide much higher heat flux than the smooth surface and thus generate 
much larger secondary bubbles. Unlike the pool boiling with a large enough boiling space, the large bubbles impinge the upper wall of the 5-mm high test channel and are not easily swept away by the small fluid velocity of $0.5 \mathrm{~m} / \mathrm{s}$ immediately. Therefore, the fresh bulk liquid can not access the heater surface easily, resulting in a earlier heater burnout. The earlier occurrence of CHF for the micro-pin-finned surfaces was also found in the boiling heat transfer experiments of our natural circulation loop (Wei et al. 2007).

\section{Enhanced Boiling Heat Transfer Mechanism for Micro-pin-Fins}

Just like the boiling heat transfer mechanism explained by Webb (1983) for the porous coating surfaces, the better nucleate boiling heat transfer performance of the micro-pin-finned chips is supposed to be the increase in the effective boiling heat transfer area due to the existence of the sidewalls of micro-pin-fins. According to the boiling phenomena taken, using a high-speed video camera, a bubble is generated in the gaps between the adjacent pin fins. Schematic of heat transfer phenomena in a gap between micro-pin-fins is shown in Fig. 10. It is assumed that a bubble generates at the root part of a micro-pin-fin. By the evaporation of the liquid nearby, the bubble grows in a narrow confined gap between pin fins, producing a very thin liquid film formed on the fin sidewall surfaces. The thin liquid film evaporates with a very large heat transfer coefficient Then a large bubble forms and stays at the top of the micro-pinfins for a certain time with continuous growth, which could also drive the liquid adjacent to the micro-pin-fin sidewall towards the top of the micro-pin-fins by suction due to the pumping action of bubble growth, and thus enhances the micro-convection of the superheated liquid along the fin sidewalls. Thus the sidewall area of the micro-pin-fin is activated for effective heat transfer and increase of liquid evaporation. The number of nucleation sites increases with increasing heat flux, thus more micro-pin-fin sidewall areas are activated and more effective heat transfer surface areas take part in the boiling heat transfer, resulting in a very small increase of wall superheat with increasing heat flux. For the flow boiling case, the nucleation in boiling is more or less affected by the fluid flow, generally resulting in a smaller slop of the boiling curves than that for the pool boiling, especial for large fluid velocity. Compared with the micro-pin-finned surfaces, the porous surface generated many bubbles in the low heat flux region due to its re-entrant or double re-entrant cavities for effectively trapping larger embryonic bubbles and increasing active nucleation sites density, which dramatically reduce incipient and nucleate boiling superheats, resulting in larger boiling heat transfer coefficients. In the high heat flux region, the micro-pin-finned chip showed excellent performance due to the increase of effective heat transfer area, but the microporous surface performance began to deteriorate due to a large amount of vapors accumulating in the porous structures which prevented the bulk of liquid from contacting the superheated wall for vaporization. The enhancement, due to the increased thermal resistance of the large amount of vapors trapped in the porous structures, tapers off noticeably as the heat flux approaches the CHF. We can see from the boiling curves of the micropin-finned surfaces that the micro-pin-finned surface can keep heat transfer performance up to the $\mathrm{CHF}$ with a wall temperature lower than $85^{\circ} \mathrm{C}$, whereas the porous surface got the $\mathrm{CHF}$ at a wall temperature higher than $85^{\circ} \mathrm{C}$ with markedly reduced heat transfer coefficients. In the high heat flux region, although the micro-pin-finned surfaces are covered with large bubbles as smooth or microporous surfaces. The capillary force generated by the bubbles drives plenty of fresh liquid into contact with the superheated wall for vaporization through the regular interconnected structures, as well as improve the micro-convection heat transfer
Fig. 10 Schematic of heat transfer phenomena within a gap between micro-pin-fins

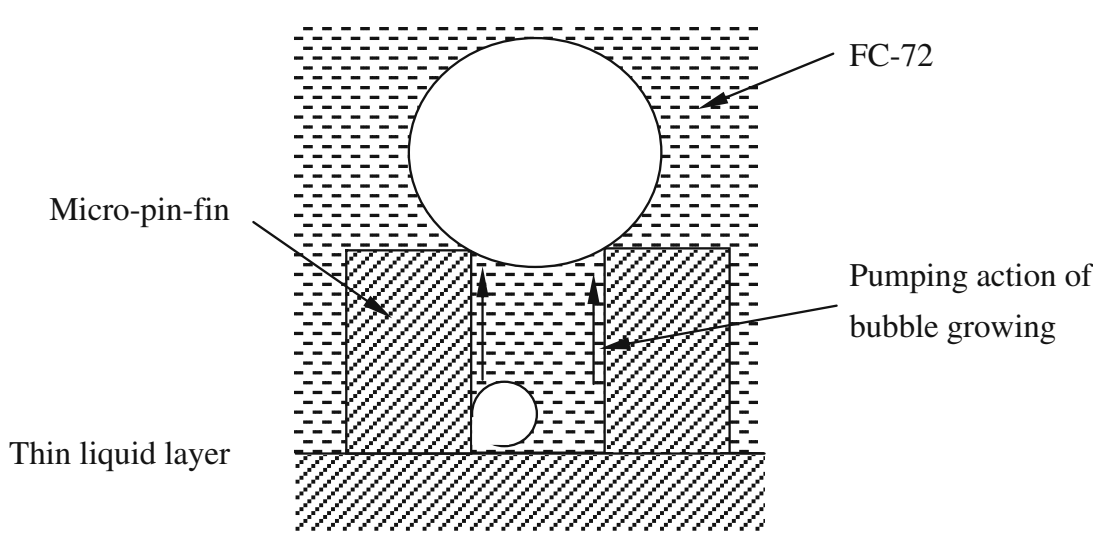


Fig. 11 Boiling heat transfer phenomena at high heat flux near CHF. a Smooth or microporous surface. b Micro-pin-finned surface
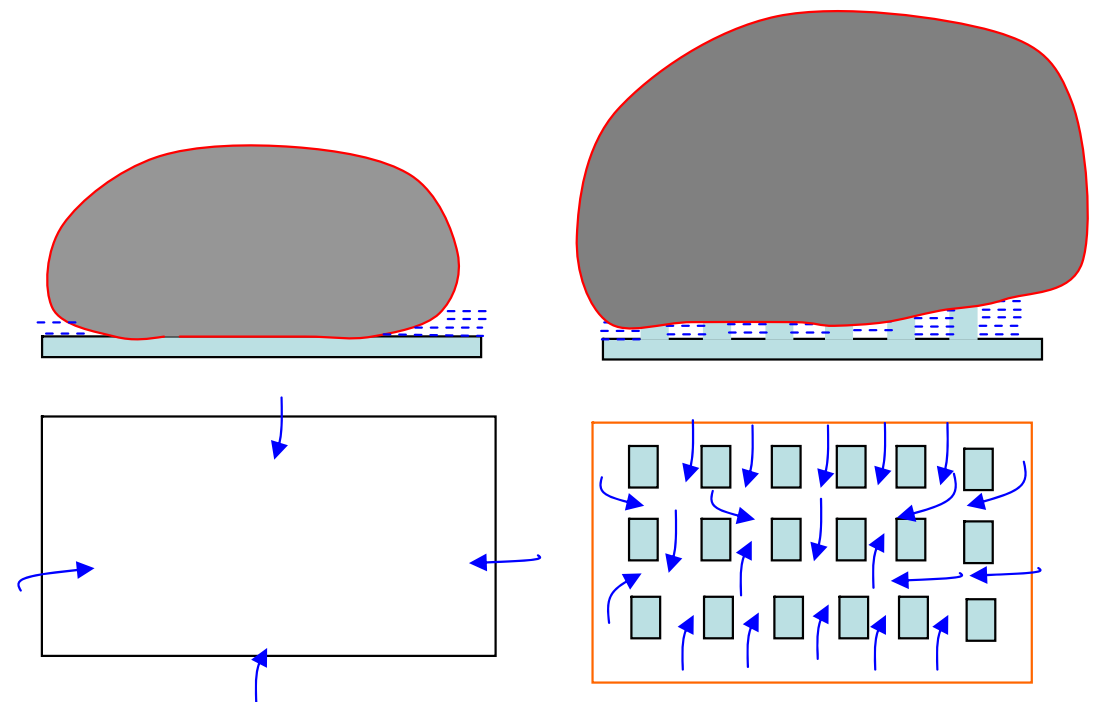

(a) smooth or micropourous surface

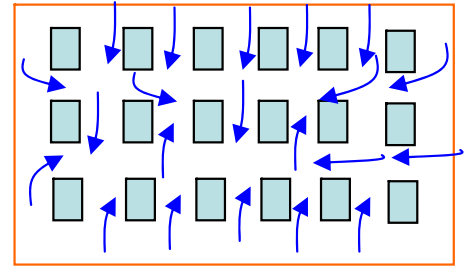

(b) micro-pin-finned surface by the motion of liquid around the micro-pin-fins, as shown in Fig. 11. These produce a high heat transfer efficiency until the capillary force arrives at its maximum value and could not overcome the hydraulic resistances of the wet liquid to access everywhere in the micro-pin-fins interconnected channel with further increase of heat flux, then the liquid near some micropin-fins is used up due to shortage of fresh liquid supply. Vapor patch is formed and soon extends to the whole surface, which finally leads to the CHF. The capillary force increases with decreasing fin pitch with a penalty that causes the hydraulic resistances of the wet liquid supply to increase. Therefore, there exists an optimum fin pitch for a compromise. In the present experimental study, the fin gap of $30-50 \mu \mathrm{m}$ appears to be a preferable size for the design of micro-pin-finned surfaces in the enhancement of nucleate boiling heat transfer.

\section{Perspective for Enhanced Boling Heat Transfer Experiment in Microgravity}

Electronics cooling by using boiling heat transfer in space and on planetary neighbors has become an increasing significant subject. For the boiling heat transfer in microgravity, the buoyancy effect becomes weak, resulting in a longer stay time for the bubble departure. These may prevent the effective access of fresh bulk liquid to the heater surface in time, resulting in a lower boiling heat transfer performance at high heat flux (Wan and Zhao 2008). How to improve boiling heat transfer effectively in microgravity is an important issue. Following the enhanced boiling heat transfer mechanisms explained in the former section, for the micro-pin-finned surfaces, it is supposed that although the bubbles staying on the top of the micro-pin-fins can not be detached soon in microgravity, the fresh bulk liquid may still access to the heater surface through interconnect tunnels formed by the micro-pin-fins due to the capillary forces, which is independent of the gravity level. Therefore, it is our great interest to study the boiling heat transfer performance of micro-pin-finned surfaces in microgravity.

In the microgravity experiment, the four kinds of micro-pin-finned chips will be tested in microgravity. The Drop Tower Beijing/NMLC will be used for providing the short-term microgravity. Figure 12 shows the schematic diagram of the Drop Tower Beijing. It is $116 \mathrm{~m}$ above the ground (including $92 \mathrm{~m}$ of the tower body and $24 \mathrm{~m}$ of the rest parts) and $8 \mathrm{~m}$ under the ground. The free drop height is about $60 \mathrm{~m}$, which provides a course of $3.6 \mathrm{~s}$ for microgravity experiments. The drop capsule is released in the atmosphere environment. To increase the microgravity level, it is designed to have inner and outer capsules with light and thin shell structure. The space between the inner capsule (experiment rig) and the outer capsule (drag shield) is evacuated to $100 \mathrm{~Pa}$. Thus, the residual gravity level using the dual-capsule may reach no more than $10^{-5} g_{0}$. The residual gravity level may be in the range of $10^{-2} \sim 10^{-3} g_{0}$ by using the single capsule.

Figure 13 shows the research project on pool boiling heat transfer in microgravity. Carefully degassed FC-72 will be used as the test liquid. A nearly atmospheric pressure is maintained by attaching a rubber bag to the test vessel. The test section assembly consisting of a 
Fig. 12 Schematic diagram of microgravity drop tower

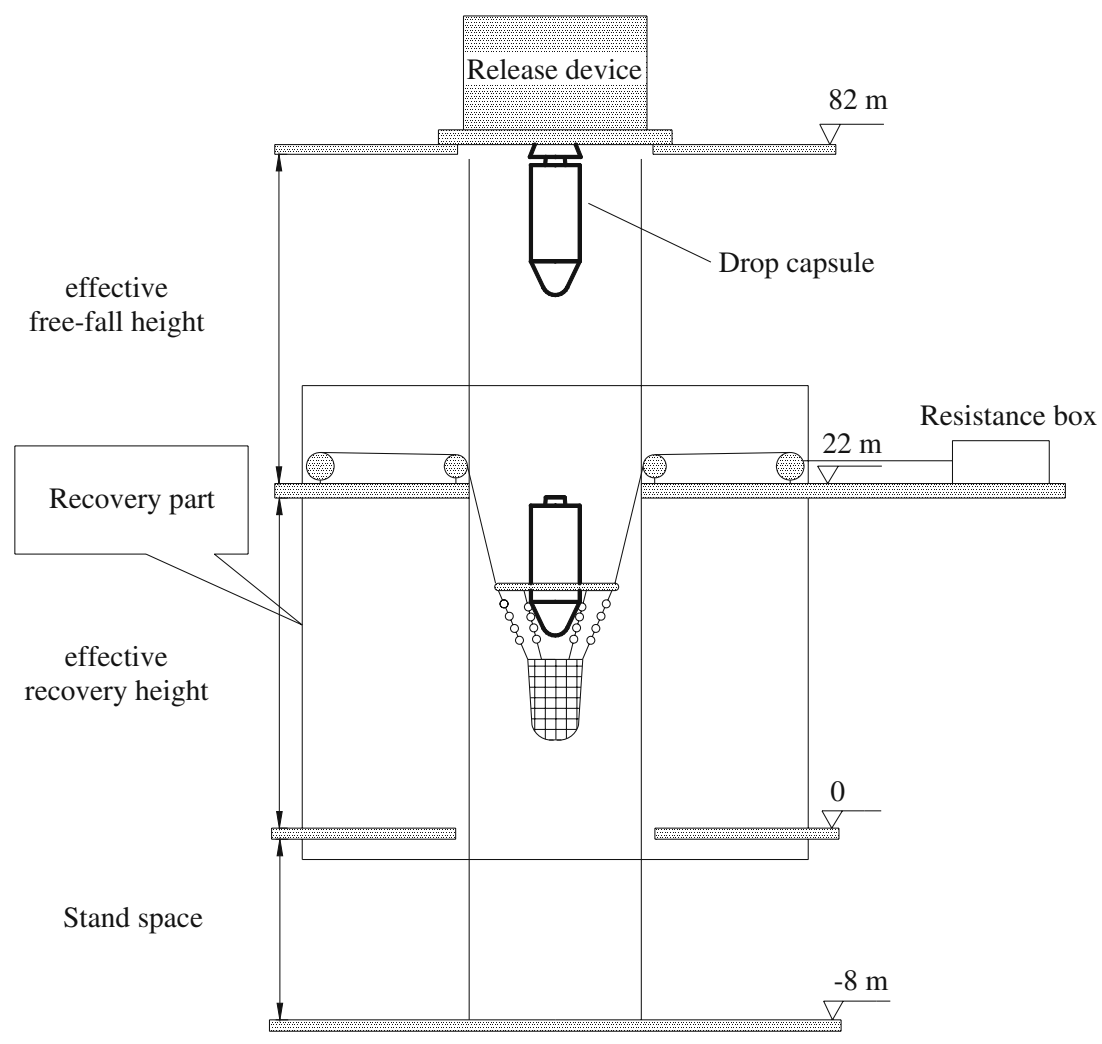

test chip bonded on a pyrex glass plate and a vacuum chuck made of stainless steel is immersed horizontally in the test container. The vacuum chuck is designed to hold the glass plate by suction and to minimize heat loss due to heat conduction through the glass plate. For the visual observation of boiling phenomena, the test container is fitted with glass windows in the up, front and back sides. Transient processes of bubble formation, growth and departure will be observed, while the boiling curves of the four micro-pin-finned surfaces will be measured at subcooling and saturated conditions. The main aim is to obtain bubble behavior and boiling heat transfer performance of the prospective micro-pinfinned surfaces in microgravity.
Fig. 13 Schematic diagram of experimental apparatus

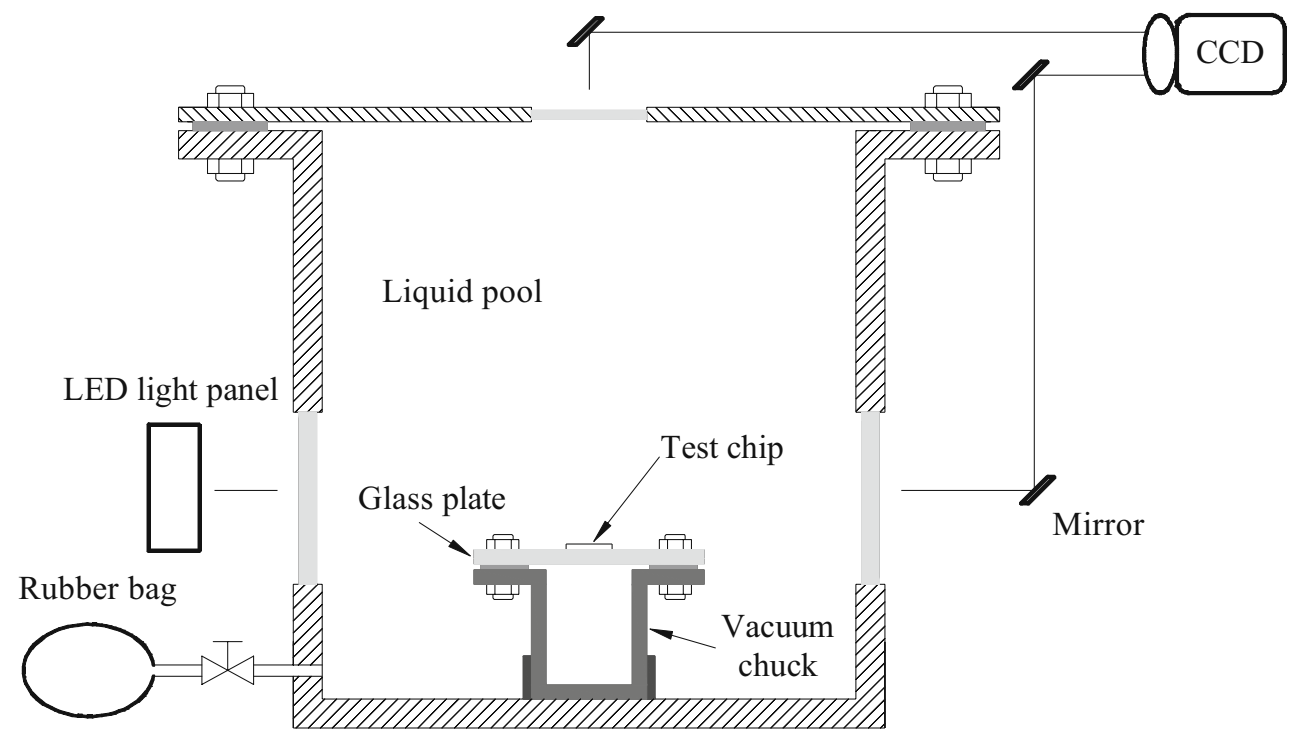




\section{Summary}

The boiling heat transfer performance of FC-72 on simulated silicon chips with micro-pin-finned surface was studied by investigating the effects of fluid velocity, subcooling and fin height. A smooth surface was also tested for comparison.

All micro-pin-fined surfaces have considerable heat transfer enhancement compared with a smooth surface, the wall superheat in the nucleate boiling region decreases in the order of chip S, PF50-60, PF30-60, PF30-120 for the same fluid velocity, showing that the boiling heat transfer can be enhanced by increasing total surface area. Chip PF50-120 with roughness on the fin flank has a double heat transfer enhancement, showing the smallest wall superheat although the surface area ratio is not the largest.

The CHF values for all surfaces increase with fluid velocity and subcooling, and the effect of fluid velocity is more noticeably. The CHF for the micro-pin-finned surfaces is more sensitive to the fluid velocity and liquid subcooling than smooth chip. For a lower liquid subcooling of $15 \mathrm{~K}$, the rate of $\mathrm{CHF}$ enhancement is increased remarkably above the fluid velocity of $1 \mathrm{~m} / \mathrm{s}$; however for a larger liquid subcooling of $35 \mathrm{~K}$, the rate of $\mathrm{CHF}$ enhancement is decreased above $1 \mathrm{~m} / \mathrm{s}$. This is due to the increased effect of single-phase forced convection heat transfer with increasing liquid subcooling and fluid velocity. The maximum $\mathrm{CHF}$ can reach nearly $148 \mathrm{~W} / \mathrm{cm}^{2}$ by chips PF30-120 and PF50-120 at $V=2 \mathrm{~m} / \mathrm{s}$ and $\Delta T_{\text {sub }}=35 \mathrm{~K}$. The wall temperature for the micro-pin-finned surfaces is less than the upper temperature limit for the normal operation of LSI chip, $85^{\circ} \mathrm{C}$.

For a higher fluid velocity of $2 \mathrm{~m} / \mathrm{s}$, the bubble nucleation is greatly affected by the forced flow and heat transfer on the chip, resulting in a smaller slope of the boiling curves.

The high boiling heat transfer performance for the micro-pin-finned surfaces is considered to be relevant to the evaporation of superheated liquid within the confined gaps between fins and micro-convection caused by thermocapillary force due to the suction of a bubble hovering on the top of micro-pin-fins. There exist optimum fin gaps for a compromise of capillary force and flow resistance.

The boiling heat transfer of the micro-pin-finned surfaces in microgravity are planned to be made in the near future. The microgravity is to be obtained by using Drop Tower Beijing/NMLC. Some major features of the measurement are described.
Acknowledgements The project is sponsored by the National Fundamental Research Program of China (no. 2006CB601203). This work is also supported by the key project of State Education Ministry of China (no. 106142) and the program for new century excellent talents in university (NCET-07-0680).

\section{References}

Anderson, T.M., Mudawar, I.: Microelectronic cooling by enhanced pool boiling of a dielecric fluorocarbon liquid. ASME J. Heat Transfer 111, 752-759 (1989)

Bergles, A.E., Chyu, M.C.: Characteristics of nucleate pool boiling from porous metallic coatings. ASME J. Heat Transfer 104, 279-285 (1982)

Chang, J.Y., You, S.M.: Heat orientation effects on pool boiling of micro-porous-enhanced surfaces in saturated FC-72. ASME J. Heat Transfer 118, 937-943 (1996)

Honda, H., Takamastu, H., Wei, J.J.: Enhanced boiling of FC-72 on silicon chips with micro-pin-fins and submicronscale roughness. ASME J. Heat Transfer 124, 383-390 (2002)

Hwang, U.P., Moran, K.F.: Boiling heat transfer of silicon integerated circuits chip mounted on a substrate. Heat Transfer Electron. Equip. ASME HTD 20, 53-59 (1981)

Kubo, H., Takamatsu, H., Honda, H.: Effects of size and number density of micro-reentrant cavities on boiling heat transfer from a silicon chip immersed in degassed and gas dissolved FC-72. J. Enhanced Heat Transfer 6, 151-160 (1999)

Kutateladze, S.S., Burakov, B.A.: The critical heat flux for natural convection and forced flow of boiling and subcooled dowtherm. In: Problems of Heat Transfer and Hydraulics of Two-phase Media, pp. 63-70. Pergamon, Oxford (1989)

Lie, Y.M., Ke, J.H., Chang, W.R., Cheng, T.C., Lin, T.F.: Saturated flow boiling heat transfer and associated bubble characteristics of FC-72 on a heated micro-in-finned silicon chip. Int. J. Heat Mass Transfer 50, 3862-3876 (2007)

Messina, A.D., Park, E.L.: Effects of precise arrays of pits on nucleate boiling. Int. J. Heat Mass Transfer 24, 141-145 (1981)

Mudawar, I., Maddox, D.E.: Critical heat flux in subcooled flow boiling of fluorocarbon liquid on a simulated electronic chip in a vertical rectangular channel. Int. J. Heat Mass Transfer 32, 379-394 (1989)

Nakayama, W., Daikoku, T., Nakajima, T.: Effects of pore diameters and system pressure on saturated pool nucleate boiling heat transfer from porous surfaces. ASME J. Heat Transfer 104, 286-291 (1982)

O'Connor, J.P., You, S.M.: A painting technique to enhance pool boiling heat transfer in saturated FC-72. ASME J. Heat Transfer 117, 387-393 (1995)

O'Connor, J.P., You, S.M., Price, D.C.: A dielectric surface coating technique to enhance boiling heat transfer from high power microelectronics. IEEE Trans. Compon. Packag. Manuf. Technol. 18, 656-663 (1995)

O'Connor, J.P., You, S.M., Chang, J.Y.: Gas saturated pool boiling heat transfer from smooth and microporous surfaces in FC-72. ASME J. Heat Transfer 118, 662-667 (1996) 
Oktay, S.: Departure from natural convection (DNC) in lowtemperature boiling heat transfer encountered in cooling micro-electronic LSI devices. In: Proceeding of 7th International Heat Transfer Conference, vol. 4, pp. 113-118. Munich (1982)

Oktay, S., Schmekenbecher, A.: Method for forming heat sinks on semiconductor device chips. U.S. Paten No. 3706127 (1972)

Phadke, N.K., Bhavnani, S.H., Goyal, A., Jaeger, R.C., Goodling, J.S.: Re-entrant cavity surface enhancements for immersion cooling of silicon multichip packages. IEEE Trans. Components Hybrids Manuf. Technol. 15, 815-822 (1992)

Rainey, K.N., Li, G., You, S.M.: Flow boiling heat transfer from plain and microporous coated surfaces in subcooled FC-72. ASME J. Heat Transfer 123, 918-925 (2001)

Ujereh, S., Fisher, T., Mudawar, I.: Effects of carbon nanotube arrays on nucleate pool boiling. Int. J. Heat Mass Transfer 50, 4023-4038 (2007)
Wan, S.X., Zhao, J.F.: Pool boiling in microgravity: recent results and perspectives for the project DEPA-SJ10. Microgravity Sci. Technol 20, 219-224 (2008)

Webb, R.L.: Nucleate boiling on porous coated surfaces. Heat Transf. Eng. 4, 71-82 (1983)

Wei, J.J., Honda, H.: Effects of fin geometry on boiling heat transfer from silicon chips with micro-pin-fins immersed in FC-72. Int. J. Heat Mass Transfer 46, 4059-4070 (2003)

Wei, J.J., Guo, L.J., Honda, H.: Experimental study of boiling phenomena and heat transfer performances of FC-72 over micro-pin-finned silicon chips. Heat Mass Transf. 41, 744$755(2005)$

Wei, J.J., Wang, Y.S., Honda, H.: Boiling heat transfer enhancement for electronic components in a natural circulation loop. In: The 6th International Conference on Multiphase Flow, Leipzig, Germany, 9-13 July 2007

Wright, N., Gebhart, B.: Enhanced boiling on microconfigured surfaces. ASME J. Heat Transfer 111, 112-120 (1989) 